\title{
Features of Electronic Circular Dichroism and Tips for its use in Determining Absolute Configuration
}

\author{
Jesús T. Vázquez \\ Instituto Universitario de Bio-Orgánica “Antonio González”, Departamento de Química Orgánica, \\ Universidad de La Laguna, 38206 La Laguna, Tenerife, Spain \\ Tel.: +34-922318581; e-mail: jtruvaz@ull.edu.es
}

\begin{abstract}
This review focuses on the general features of electronic circular dichroism (ECD) as applied in determining the absolute configuration of organic compounds. The high sensitivity and straightforward spectral interpretation of the exciton chirality method makes this approach very useful, and complementary to X-ray crystallography. A brief tutorial is provided on ECD, with precautions and tips for using it, especially the exciton chirality method. The spectral ECD of several examples are analyzed. (C) 2017 Elsevier Science. All rights reserved
\end{abstract}

\section{Introduction}

Nowadays, Electronic Circular Dichroism (ECD) has become a powerful technique for establishing the absolute configuration of organic compounds, of both natural and synthetic origin. Since the 1960s, ECD has been displacing Optical Rotatory Dispersion (ORD), ${ }^{1,2,3}$ another useful technique for structural, stereochemical and conformational studies in organic chemistry.

This review is not intended to give an large number of recent references, but gives selected examples to illustrate theoretical and practical features and applications of ECD ${ }^{4-}$ 8 in determining the absolute configuration of organic compounds. Optical activity is the result of the different indices of refraction for left and right plane-polarized light when it travels through chiral structures such as small organic molecules (sugars, natural products, peptides) or macromolecules (proteins). ${ }^{9-11}$ Normally the rotation occurs for the strongest yellow band of sodium light, called the D-line, at $589 \mathrm{~nm}$. The variation of this optical activity with wavelength gives rise to an optical rotatory dispersion curve (ORD) (not a spectrum, since electronic transitions are not necessarily involved).

There are two types of ORD curves, those called plain or normal curves, and Cotton-effect curves. The former result from chiral organic molecules without an absorption band (chromophore or light-absorbing group) within the spectral range under analysis, while the Cotton-effect curves derive from those chiral molecules that display a maximum or a minimum, or both, in the region under study. This is because of abnormal behavior of the rotatory power at the wavelength of an absorption band (chromophore). It was named the Cotton effect after the person who first observed this phenomenon. It is said to be a positive or negative Cotton-effect curve, depending on the sign of the first extremum observed at the longer wavelength (Figure 1).

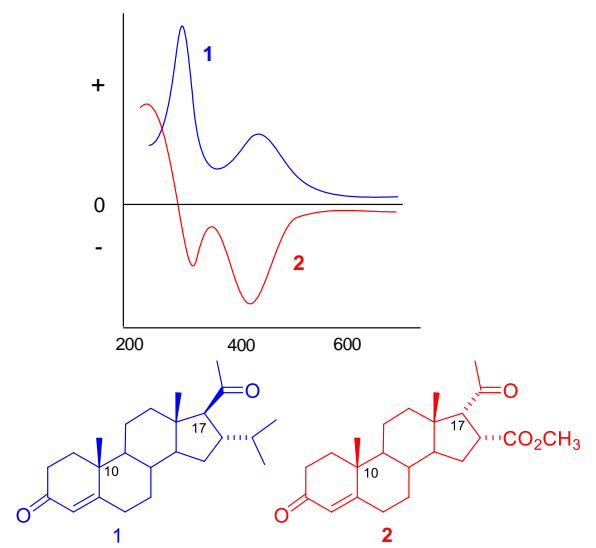

Figure 1. ORD curves of compounds 1 (positive, blue) and $\mathbf{2}$ (negative, red).

Unlike ORD, circular dichroism (ECD) is observed for those chiral molecules that absorb light in the region under study. Thus, ECD is the difference in the absorption of lefthanded circularly polarized light and right-handed circularly polarized light. Therefore, ECD is a spectroscopic technique, since there is light-absorption, and yields spectra instead of curves, although they are usually called curves.

Since ECD requires optically active chromophores, the following classification is very useful (Figure 2):

- Non-chiral chromophores and molecules, which lead to non-active ECD. 
- Chiral molecules without chromophores, which also lead to non-active ECD, but can become ECD-active by introducing a chromophore. For instance, the chemical transformation of an alcohol into a $p$-substituted benzoate.

- Chiral chromophores and molecules (inherently chiral chromophores). This type of chromophore (type 1) exhibits strong ECD.

- Non-chiral chromophores located in chiral molecules (inherently achiral but chirally-perturbed chromophores). This type of chromophore (type 2) shows weak ECD.
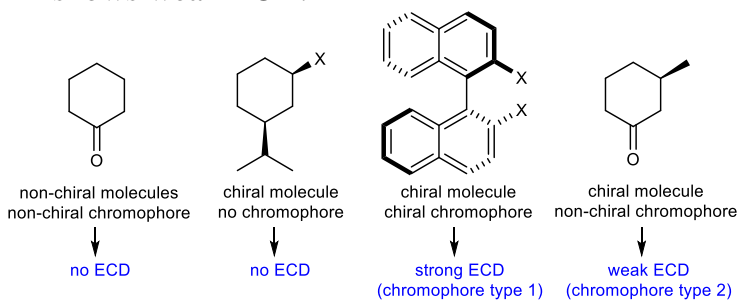

Figure 2. Classification of optically active chromophores.

Different types of ECD spectra can be expected, (i) those having a single (positive or negative) Cotton effect; (ii) those with multiple Cotton effects, where two or more Cotton effects of equal or different signs are observed (Figure 3); and (iii) those called split or exciton ECD spectra. This last is based on the through space interaction of the electric transition moment of two chromophores, which gives rise to an excited state split into two energy levels (exciton chirality method).

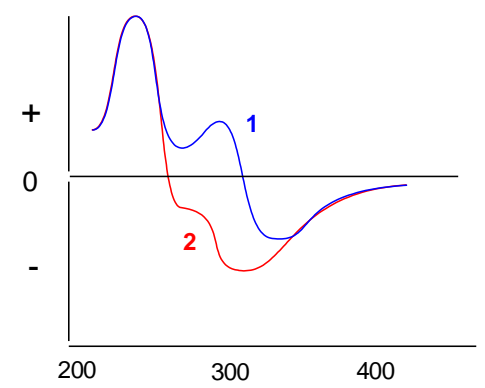

Figure 3. ECD spectra of compounds 1 (negative, blue) and $\mathbf{2}$ (negative, red).

ORD versus ECD. The Cotton effects observed in the ORD curves of compounds $\mathbf{1}$ and $\mathbf{2}$ (Figure 1) are the result of the interaction between plane-polarized light and each stereogenic carbon in the molecules, in addition to the anomalous interaction with the chromophores present. Therefore, correlation between the ORD curves and the stereochemistry of these compounds is difficult.

However, ECD spectra of compounds 1 and $\mathbf{2}$ (Figure 3) are almost superpimposable except for the region just below $300 \mathrm{~nm}$ ( $\mathrm{n} \rightarrow \pi^{*}$ transition of the keto chromophore) which are of opposite signs. The Cotton effects above 300 and around $240 \mathrm{~nm}$ correspond to the $\mathrm{n} \rightarrow \pi^{*}$ and $\pi \rightarrow \pi^{*}$ transitions of the $\alpha, \beta$-unsaturated ketone, respectively. Therefore, the correlation and interpretation of the ECD data with the stereochemistry of these molecules is simpler. The different sign of the Cotton effect below $300 \mathrm{~nm}$ reveals the opposite absolute configuration at carbon 17 , the nearest to the keto group, while the similarity of the rest of the spectra confirm the same absolute configuration for those stereogenic carbons near the $\alpha, \beta$-unsaturated ketone, mainly carbon 10 .

The ease of interpretation of the ECD spectra means this technique has been shifting the ORD. So, this work will concentrate on ECD (electronic circular dichroism).

Tip 1. There is a straightforward correlation between the wavelength of a Cotton effect in the ECD spectra and the wavelength of its UV absorption transition.

Tip 2. Enantiomers exhibit identical ECD spectra but of opposite signs.

Tip 3. The sign of a Cotton effect depends mainly on the absolute configuration of the nearest stereogenic carbon to the corresponding absorption band.

Many effective empirical rules ${ }^{1-4,6-8}$ have been proposed, those by pioneer researchers such as C. Djerassi, P. Crabeé, and G. Snatzke being very useful for establishing absolute configurations of organic compounds. Further developments came with the exciton chirality method, ${ }^{5}$ mainly through the seminal scientific contribution of $\mathrm{N}$. Harada and K. Nakanishi. This method is a non-empirical one, so comparison with any other compound or its ECD data is not necessary at all. This powerful and sensitive technique allows the absolute configuration of organic compounds to be determined by non-empirical means, via a straightforward spectral interpretation.

ECD is also applied in conformational analysis in general, to small to medium size molecules in solution, ${ }^{12}$ as well as macromolecules, especially proteins. ${ }^{10}$

In practice, this information is obtained by:

1. Spectral comparison with samples possessing very similar structures with known absolute configurations. For example, the analysis already mentioned of compounds $\mathbf{1}$ and 2.

2. Using empirical rules. ${ }^{1-4,6-8}$ There are many effective empirical rules for olefins, dienes, ${ }^{13}$ allylic alcohols and esters, saturated ketones (Octant Rule), ${ }^{14}$ aldehydes, sulfoxides, ${ }^{15}$ and so on. Due to the empirical character of these rules, they are not dealt with herein.

3. The exciton chirality method (non-empirical method). ${ }^{5,6,16}$ This requires the presence of at least two chromophores with high molar extinction coefficients $(\varepsilon)$.

Before continuing it is important to clarify some basic ideas. Figure 4 shows how the sign of the ECD spectrum of 3-methylcyclohexanone changes with the conformation of the chair (for a fixed absolute configuration) or conversely with the absolute configuration (for a fixed conformation). In this case, the widely known Octant Rule $^{1-4,14}$ can easily correlate the experimental sign with the absolute configuration / conformation once the conformation / absolute configuration, respectively, is known. 
<smiles>O=[R]1CCCC(=O)C(=O)C1</smiles>

Figure 4. Correlation between the ECD sign and the conformation/absolute configuration.

Tip 4. This technique can determine absolute configurations and conformations, but not both simultaneously.

Normally, the conformation of a molecule is determined by analysis of the NMR coupling constants $(J)$ and/or nOe experiments. Moreover, computational methods are recommended for non-rigid compounds. Therefore, once the conformation has been established, the four possibilities shown in Figure 4 are reduced to only two of opposite sign, and the absolute configuration can be determined.

Tip 5. Since ECD is very sensitive to temperature and solvent, use of the same solvent is recommended for both techniques, NMR and ECD.

The dibenzoate chirality method, ${ }^{17}$ a variety of the more general ECD exciton chirality method ${ }^{5,6,16}$ is based on the through-space interaction between the electric transition moments $\left({ }^{1} \mathrm{~L}_{\mathrm{a}}\right)$ of two chromophores. This gives rise to an excited state split into two energy levels, the energy gap $2 \mathrm{~V}_{\mathrm{ij}}$ being called Davydov splitting (Figure 5). Excitations to these levels lead to an ECD spectrum with two Cotton effects of opposite signs, called a "split" ECD curve. The chiral environment of the two chromophores determines the sign of the Cotton effects, the sign of the exciton chirality being that of the first Cotton effect that occurs at longer wavelengths. Figures 6 and 7 illustrate this. The wavelength of the UV and ECD spectra of the mono-psubstituted benzoate are almost the same and the intensity $\Delta \varepsilon^{18}$ of the Cotton effect is very low (309 nm, $\left.\Delta \varepsilon=+2.9\right)$. On the other hand, the ECD spectrum of the di- $p$ substituted dibenzoate shows two intense Cotton effects of opposite signs, negative at $320 \mathrm{~nm}, \Delta \varepsilon=-63.1$, and positive at $295 \mathrm{~nm}, \Delta \varepsilon=+39.7$, centered at UV wavelength $308 \mathrm{~nm}$. This is an excellent example of a split ECD spectrum. The high intensity of the two Cotton effects confirms the exciton interaction between these chromophores, rather than two independent Cotton effects. More importantly, the negative sign of the first Cotton effect, or the sign of the amplitude $A,{ }^{19}$ indicates a negative chirality, i.e., a left-handed screwness between the transition dipole moments of the two chromophores (Figure 5).

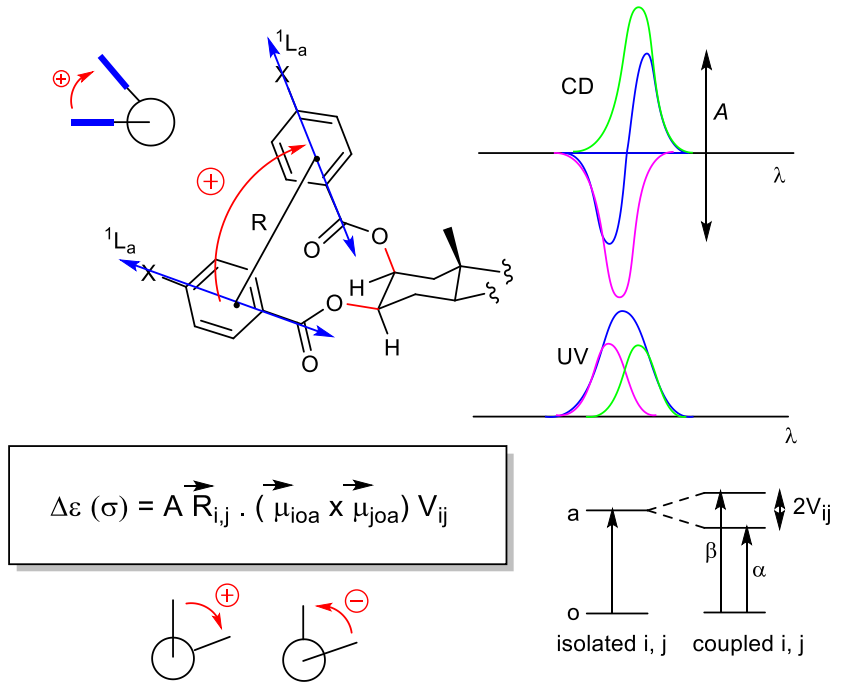

Figure 5. Nondegenerate system in which chromophoric groups $\mathrm{i}$ and $\mathrm{j}$ undergo $\mathrm{o} \rightarrow \mathrm{a}$ transitions to give split levels separated by $2 V_{\mathrm{ij} .}$.

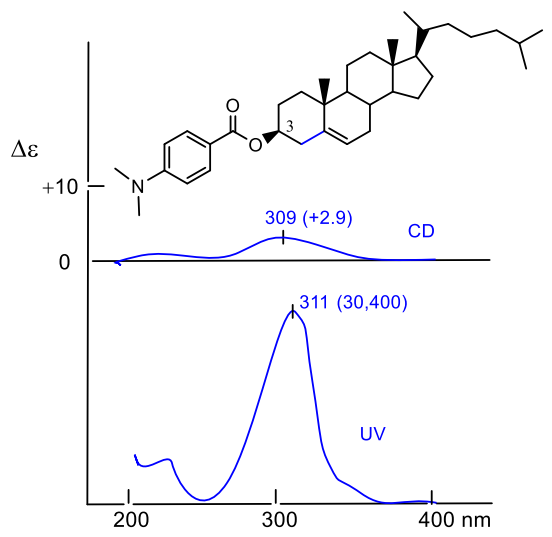

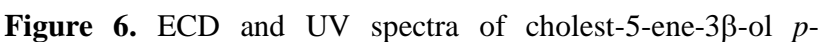
dimethylaminobenzoate in $1 \%$ dioxane/EtOH. ${ }^{5}$

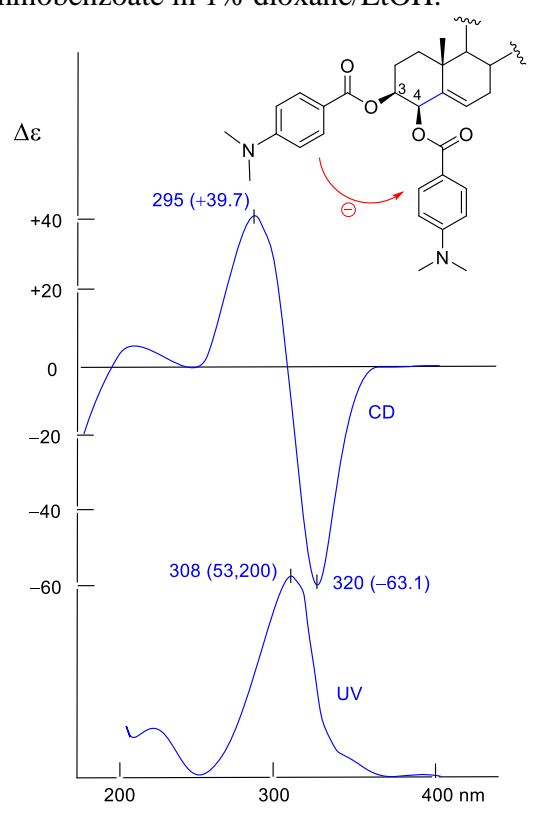

Figure 7. ECD and UV spectra of cholest-5-ene-3 $3,4 \beta$-diol bis $(p$ dimethylaminobenzoate) in EtOH. ${ }^{5}$ 
It is important to know the direction of the electric transition dipole moment in order to apply the appropriate screwness. In the case of $p$-substituted benzoates the intramolecular charge transfer transition $\left({ }^{1} \mathrm{~L}_{\mathrm{a}}\right)$ is polarized along the long axis of the chromophore (Figure 5), almost parallel to the $\mathrm{C}-\mathrm{O}$ bonds (red color). Ortho- and metasubstituted benzoates are therefore not suitable for the ECD exciton chirality method. Thus,

Tip 6. Chromophores should have high symmetry and molar extinction coefficients higher than 5,000.

The ${ }^{1} \mathrm{~L}_{\mathrm{b}}$ transition of the benzene ring shows a weak single Cotton effect (no split ECD) owing to the rather weak intensity of this band.

The intramolecular charge transfer band $\left({ }^{1} \mathrm{~L}_{\mathrm{a}}\right)$ of the $p$ substituted benzoate (Scheme 1) undergoes a bathochromic (or red shift) and hyperchromic (higher intensity) effect with electron-donating or -withdrawing groups in such position, ${ }^{5}$ the $p$-bromobenzoate chromophore being one of the most used.

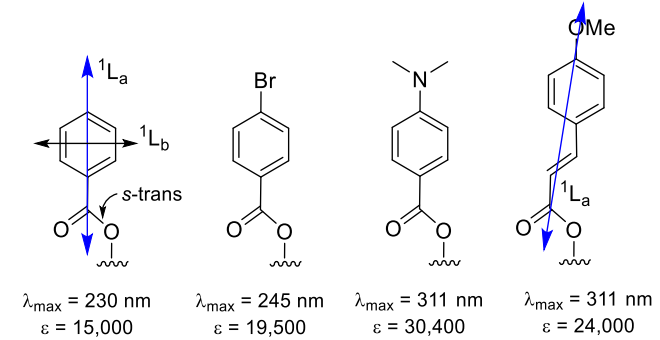

Scheme 1. Some suitable chromophores for the exciton chirality method; data for the ${ }^{1} \mathrm{~L}_{\mathrm{a}}$ band in $\mathrm{EtOH}$.
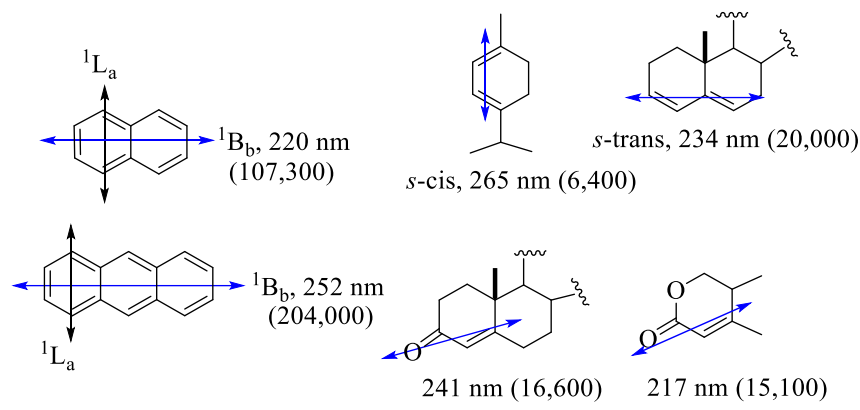

Scheme 2. Some other suitable chromophores for the exciton chirality method; data for the ${ }^{1} \mathrm{La}_{\mathrm{a}}$ band or $\pi \rightarrow \pi^{*}$ transition, in EtOH.

Tip 7. From the practical point of view, it is advisable to obtain the concentration of a sample for ECD analysis from its UV spectrum (Beer-Lambert law: $A=\varepsilon \mathrm{c} 1$ ). The value of the absorbance $(A)$ or optical density should be less than 1.2 to avoid deviation of the linearity. ${ }^{20,21}$

Tip 8. Furthermore, the intensity of the photomultiplier should be less than $550 \mathrm{v}$ to obtain an accurate and precise determination.

This was confirmed in a series of studies where the discrimination and direct determination of many $\beta$-lactam antibiotics were validated by analysis of variance. The method was successfully applied to the direct determination of these drugs in oral suspension, injections, and capsules, ${ }^{22}$ as well as in human urine, ${ }^{23}$ and human serum. $^{24}$

Some general features of the exciton chirality method are:

1. The amplitude of the split Cotton effects depends on the interchromophoric distance $\mathrm{R}_{\mathrm{ij}}$. the larger the distance the lower the amplitude. Therefore, remote chromophores exhibit weaker split Cotton-effect curves, but generally the signs of the first/second exciton Cotton effects are in agreement with the chirality between the chromophores. Clear exciton coupling between $p$-susbtituted benzoates has been observed up to a distance of $13 \AA$. For much larger distances, red-shifted chromophores have been developed (see below).

2. The equation in Figure 5 shows that the intensity of the Cotton effects $(\Delta \varepsilon)$ depends on the cross product of the electric transition moments $\mu_{\mathrm{ioa}}$ and $\mu_{\mathrm{joa}}$, therefore the exciton chirality and the intensities depend on the angles between them. At $0^{\circ}$ and at $180^{\circ}$ there is no exciton coupling, the experimental maxima being around $70^{\circ}$ (Figure 8).

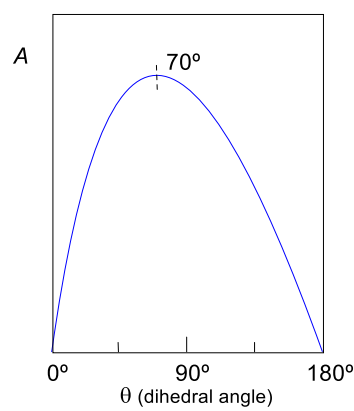

Figure 8. Relationship between the dihedral angle of the chromophores and the intensities of the exciton Cotton effects (or amplitude, $A=\Delta \varepsilon_{1}-\Delta \varepsilon_{2}$ ).

3. The exciton (pairwise) interaction can occur between two different electric transition moments (two chromophores located at different wavelengths or $\left.\lambda_{\max }\right)$. As expected, the intensity of the Cotton effects decreases as the $\lambda_{\max }$ increases, although the sign of the amplitude or the first Cotton effect remain unchangeable. Both are indicative of the exciton chirality. Excellent ECD coupling has been observed between the $p$-bromobenzoate $(245 \mathrm{~nm})$ and the $p$-methoxy-cinnamate $(311 \mathrm{~nm})$ chromophores. $^{5}$ 4. Furthermore, the additivity relation in multiple chromophoric systems allows an easy spectral interpretation of this type of compounds, since the observed ECD spectrum is the sum of ECDs arising from all pairwise interactions present in the system (Scheme 3 ). That is, the ECD spectrum of a system composed of three interacting chromophores $\mathrm{XYZ}$ is the sum of the ECDs arising from $\mathrm{X} / \mathrm{Y}, \mathrm{X} / \mathrm{Z}$ and $\mathrm{Y} / \mathrm{Z}$ interactions. The general validity of the pairwise additivity in exciton-coupled systems holds independently of whether the interacting chromophores are the same (homo interactions) ${ }^{25}$ or not (hetero interactions). ${ }^{26}$ 


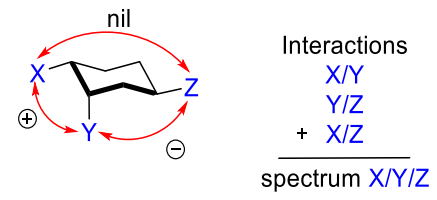

Scheme 3. Pairwise interactions of a system composed of three chromophores. In the present case, $\mathrm{X} / \mathrm{Y}$ is positive, $\mathrm{Y} / \mathrm{Z}$ is negative, and $\mathrm{X} / \mathrm{Z}$ is nil due to the coplanarity between $\mathrm{X}$ and $\mathrm{Z}$ (dihedral angle $=0^{\circ}$ ).

As an example, Figure 9 shows the observed and calculated ECD spectra of methyl 2,3-di- $p$ bromobenzoate-4,6-di- $p$-methoxycinnamate $\alpha$-D-galacto pyranoside or gal-BBCC, a compound having 6 pairwise interactions (derivatization of the four positions is represented in the order $2,3,4,6$ by $\mathrm{A}=$ acetate, $\mathrm{B}=p$ bromobenzoate, $\mathrm{C}=p$-methoxycinnamate). In this case, spectral summation of their pairwise interactions, the four hetero interactions (gal-ABCA, gal-BAAC, gal-BACA, and gal-ABAC) and the two homo interactions (galBBAA, and gal-AACC) led to an excellent calculated ECD spectrum compared to that observed in the 200-400 nm region.

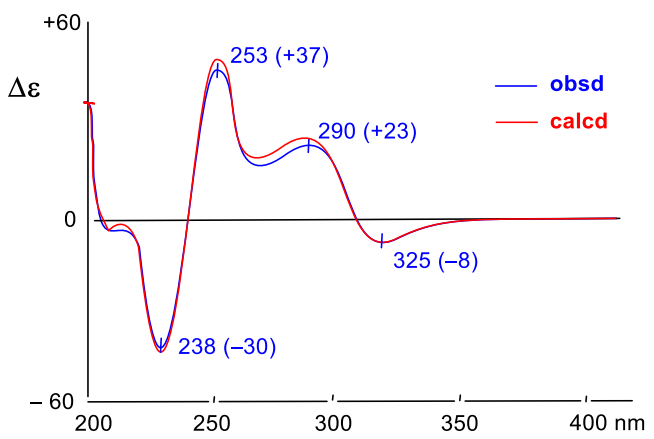

Figure 9. Comparison between calculated and observed spectra of a galactopyranoside derivative (gal-BBCC, in $\mathrm{CH}_{3} \mathrm{CN}$ ).

The "bichromophoric" exciton chirality method has been successfully applied to find the relative and absolute configuration of acyclic 1,2,3-triols, 1,2,3,4-tetrols, and 1,2,3,4,5-pentols by ECD after a simple, two-step derivatization. ${ }^{27}$ Selective 9-anthroylation $(253 \mathrm{~nm}, \varepsilon=$ $185,000)$ of primary hydroxyl followed by per- $p$-methoxycinnamoylation $(311 \mathrm{~nm}, \varepsilon=24,000)$ of secondary hydroxyls led to bichromophoric derivatives. Their CD spectra are characteristic and predictable for each stereochemical pattern (Scheme 4). Similarly, a general procedure for assigning the absolute configuration of aminopolyols has been reported. ${ }^{28}$

The absolute configurations of many molecules of different origin and size have been determined by the exciton chirality method. In the following, some examples are shown to explain some of the features, precautions and tips mentioned above, among others.

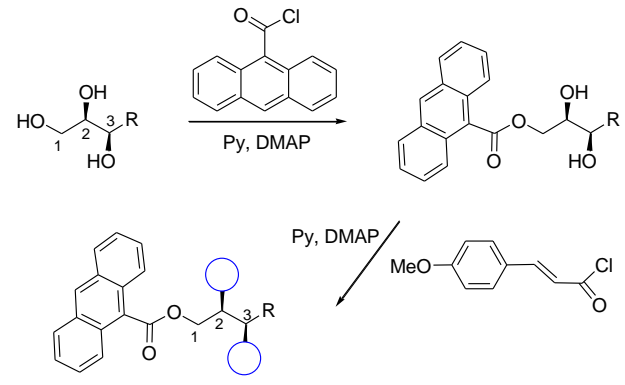

Scheme 4. Two steps derivatization for acyclic 1,2,3-triols, 1,2,3,4-tetrols, and 1,2,3,4,5-pentols.

Let us start with some sesquiterpenes isolated from Maytenus chubutensis ${ }^{29}$ where the chromophores are attached to a rigid dihydro- $\beta$-agarofuran skeleton and therefore without conformational problems. The structural difference between these sesquiterpenes is the degree of acetylation, so compound $\mathbf{3}$ was chosen to introduce a second benzoate (compound 4) and apply the dibenzoate chirality method, an extension of the circular dichroism exciton chirality method. The first Cotton effect at $237 \mathrm{~nm}$ $(\Delta \varepsilon=-19.3)$ and the second at $217 \mathrm{~nm}(\Delta \varepsilon=+1.8)$ determined the absolute configuration of these sesquiterpenes as shown. In addition, an ECD study of compound 5, which showed a positive Cotton effect at 290 $\mathrm{nm}(\Delta \varepsilon=+3.6)$ corresponding to the $\mathrm{n} \rightarrow \pi^{*}$ transition of the keto group (octant rule) ${ }^{14}$ supported the same absolute configuration as that determined by the exciton chirality method.

Other new sesquiterpene esters were isolated from Maytenus disticha, ${ }^{30}$ some of them having two natural benzoates as compound 6. The ECD spectrum of this dibenzoate showed intense split Cotton effects of the exciton coupling type, a positive first Cotton effect at 231 $\mathrm{nm}(\Delta \varepsilon=+21.1)$ and a negative Cotton effect at $222 \mathrm{~nm}$ $(\Delta \varepsilon=-10.9)$, in total agreement with its absolute configuration.
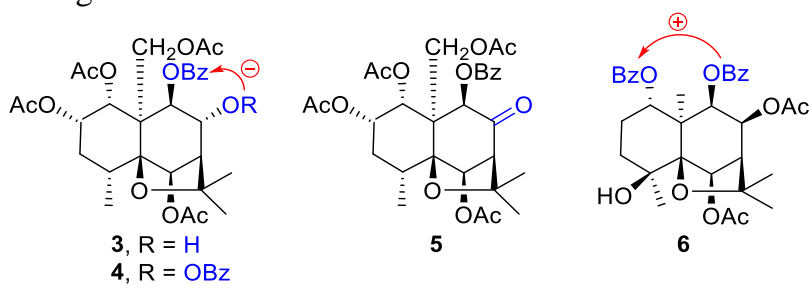

Six sesquiterpenes were isolated From Maytenus magellanica ${ }^{31}$ with the dihydro- $\beta$-agarofuran skeleton but displaying a novel substitution pattern. Their structures were elucidated by NMR spectroscopic studies and their absolute configurations by applying the ECD exciton chirality method. Striking ECD features were observed, compound 7 showed a positive Cotton effect at $237 \mathrm{~nm}(\Delta \varepsilon$ $=+21.1)$ and a negative Cotton effect at $220 \mathrm{~nm}(\Delta \varepsilon=$ -8.0). This split ECD curve assigned the absolute chirality of the benzoates and therefore of the rest of the stereogenic carbons except carbon 3, for which no relative configuration with the rest of the molecule was available. Thus, benzoylation of $\mathbf{7}$ led to the tribenzoate $\mathbf{8}$, which did 
not show any split ECD curve. The opposite 1,3 and 1,9 pairwise interactions cancelled each other out and the 3,9 pairwise interaction was almost coplanar and therefore null. This result pointed to the absolute configuration shown for carbon 3. However, clearer ECD results could be obtained by changing the chromophore at carbon 3 . This time, a $p$-methoxycinnamoylation was carried out to lead to the bichromophoric compound $\mathbf{9}$, which exhibited the ECD spectrum shown in Figure 10. This ECD spectrum can be divided into a positive homo pairwise interaction, between the benzoates at positions 1 and 9, $240 \mathrm{~nm}(\Delta \varepsilon=$ $+13.2)$ and $225 \mathrm{~nm}(\Delta \varepsilon=-9.0)$, and a negative hetero pairwise interaction, between the benzoate at position 1 and the $p$-methoxycinnamate, $306 \mathrm{~nm}(\Delta \varepsilon=-12.7)$.

Tip 9. This is an excellent example of the use of two different chromophores for absolute configuration determination of organic molecules, overcoming the above-mentioned ECD cancellation observed with $\mathbf{8}$.
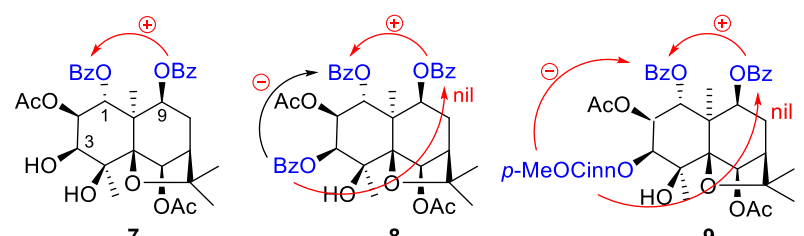
8

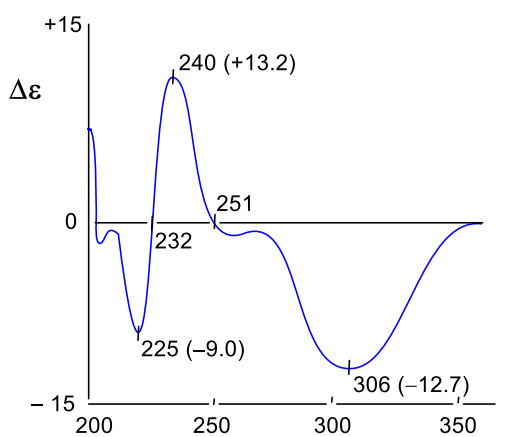

Figure 10. Structures of the two sesquiterpenes 6 and 7 and ECD spectrum of compound $7\left(\mathrm{CH}_{3} \mathrm{CN}\right)$.

Recently 10 new dihydro- $\beta$-agarofuran sesquiterpenes with potential antitumor-promoting effects were isolated and structurally determined, including their absolute configuration by ECD. ${ }^{32}$

A different, more complex case is that of the brevetoxins $\mathrm{B}$ (BTX-B) and A (BTX-A) isolated from the "red tide" of dinoflagellate Ptychodiscus brevis Davis. The structure of the former (BTX-B) was determined by X-ray crystallography, although its absolute configuration was based on ECD experiments. ${ }^{33}$ In its UV spectrum in $\mathrm{MeOH}, \mathrm{BTX}-\mathrm{B}$ showed a transition at $208 \mathrm{~nm}(\varepsilon$ 16,000) corresponding to $\pi \rightarrow \pi^{*}$ enal, multiple Cotton effects and in its ECD spectrum $(\mathrm{MeOH}): 225(\Delta \varepsilon-3.93$, ene-lactone $\left.\pi \rightarrow \pi^{*}\right), 257\left(\Delta \varepsilon+6.77\right.$, ene-lactone $\left.\mathrm{n} \rightarrow \pi^{*}\right)$, and $329 \mathrm{~nm}$ $\left(\Delta \varepsilon+0.16\right.$, enal $\left.\mathrm{n} \rightarrow \pi^{*}\right)$.

The free rotation of the enal group together with the weak UV transitions prevent any absolute configuration determination from this data. However, transforming the present chromophores into non-chromophores and introducing a new 1,2-di-p-bromobenzoate system into ring $\mathrm{H}$ (Scheme 5, 12), enabled the exciton chirality method to be applied in determining the absolute configuration of this molecule nonempirically. The relative configuration of the two new stereogenic carbons and the crown conformation adopted by the eight-membered ring was determined by NMR analysis of the coupling constant as well as by molecular mechanics (Allinger MM2 forcefield program).

The structure of the minor but more potent toxin BTX-A was later determined by X-ray crystallography from its dimethyl acetal derivative, ${ }^{34}$ and its absolute configuration from a chiral dioxolane derivative and X-ray analysis. ${ }^{35}$ The absolute configurations obtained for BTX-A and BTX$\mathrm{B}$ were in agreement with that obtained previously for BTX-B by ECD.
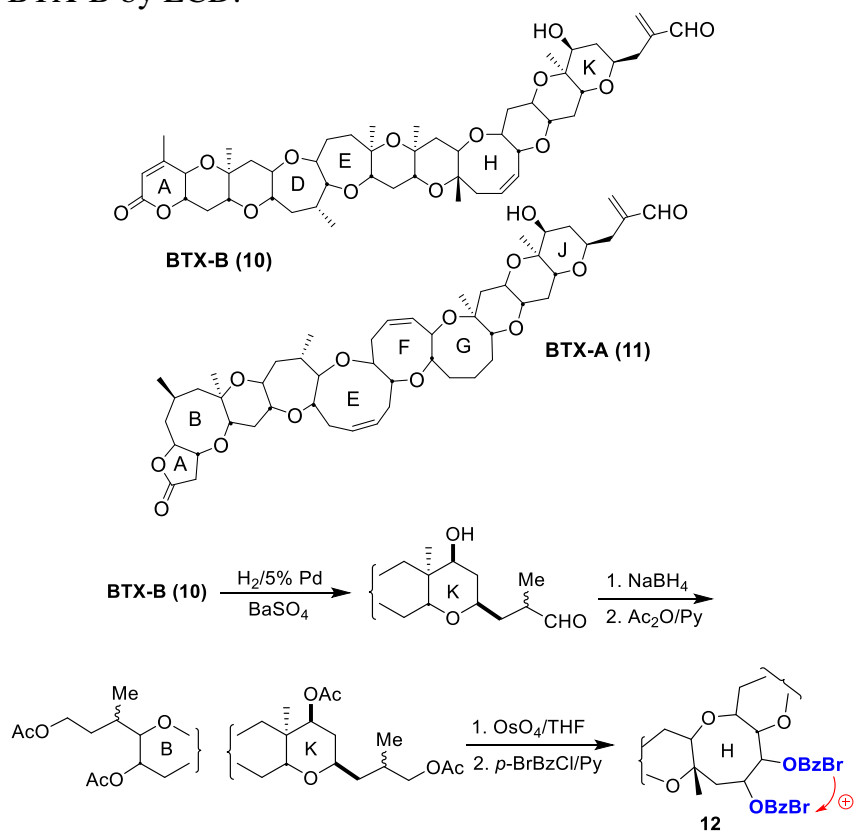

Scheme 5. Structures of BTX-B and BTX-A, and chemical transformation of BTX-B in its di-p-bromobenzoate derivative 12.

Almost simultaneously, the absolute configuration of BTX-A was reported by ECD spectral comparison with BTX-B. ${ }^{36}$ Thus BTX-A shows a band at $208 \mathrm{~nm}(\varepsilon 11,000)$ in its UV spectrum in $\mathrm{MeOH}$, corresponding to the $\pi \rightarrow \pi^{*}$ of enal transition, and a shoulder at $215 \mathrm{~nm}(\varepsilon 8700)$ of the $\mathrm{n} \rightarrow \pi^{*}$ of lactone. Its ECD spectrum $(\mathrm{MeOH})$ exhibited three Cotton effects: 213 ( $\Delta \varepsilon=-1.64, \mathrm{n} \rightarrow \pi^{*}$ of lactone), $235(\Delta \varepsilon=+1.23$, assignment unclear $)$, and $329 \mathrm{~nm}(\Delta \varepsilon=$ $+0.15, \mathrm{n} \rightarrow \pi^{*}$ of enal). Although weak, this enal transition is very similar to that of BTX-B $(\Delta \varepsilon=+0.16)$, indicating that the absolute configuration of the enal moieties of both toxins are identical. Its absolute configuration was in this way perfectly determined, as that of BTX-B was submitted to the exciton chirality method, and there was no need for any chemical transformation. 
Tip 10. ECD spectral comparison can be an excellent and simple way in determining absolute configuration, as in the case of BTX-A.

The scope and limitations of intense absorbance porphyrin chromophores for stereochemical studies $(\varepsilon=350,000)$ were studied in BTX-B. The results showed that excitoncoupled ECD were obtained over interchromophoric distances up to $50 \AA$ A. This fact makes pophyrins useful chromophores for applying the exciton coupled CD method to structural studies of biopolymers. ${ }^{37}$

Allylic benzoates are also very useful systems for the determining organic molecules, being another extension of the exciton chirality method. This is a nondegenerate system composed of two different chromophores: a benzoate chromophore that exhibits an allowed $\pi \rightarrow \pi^{*}$ intramolecular charge transfer band $\left({ }^{1} \mathrm{~L}_{\mathrm{a}}\right)$ at $230 \mathrm{~nm}$, and a C-C double-bond chromophore also with an allowed $\pi \rightarrow \pi^{*}$ transition around $195 \mathrm{~nm}$. Both transitions are polarized along the long axes of the chromophores. This method has a theoretically sound basis. ${ }^{38,39}$

Starting with cyclic allylic benzoates, the choles-4-en-3 $\beta$ ol benzoate 13 exhibited a negative Cotton effect $(\Delta \varepsilon=-$ 8.7 ) in total agreement with the negative exciton chirality between the benzoate and the double-bond chromophores (Figure 11). For this type of exciton coupling, it is usual not to detect the second Cotton effect of the split ECD. This finding has been attributed to the participation of the benzenoid ${ }^{1} \mathrm{~B}$ transition (around $200 \mathrm{~nm}$ ) of the benzoate chromophore, and/or other transitions of the double bond.

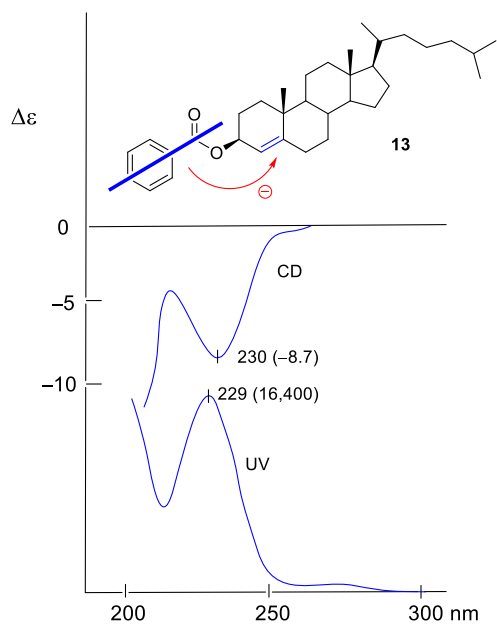

Figure 11. Structure, chirality, and UV and ECD spectra of choles-4-en-3 $\beta$-ol benzoate (13) in EtOH.

Other interesting examples are the novel sesquiterpenes caespitol (14) and isocaespitol (15). ${ }^{40}$ Although their structures were determined by X-ray crystallography, their absolute configuration could not be unambiguously determined by this method, since the crystallographic differences between Friedel pairs were small. Therefore, the exciton chirality method was recurred to. However, to apply the allylic benzoate method the sesquiterpenes had to be derivatized. Oxidation of caespitol (14) and isocaespitol
(15) with Jones reagent led to the unsaturated ketones $\mathbf{1 6}$ and 17, respectively. Reduction with diisobutylaluminium hydride gave both $\alpha(\mathbf{1 8 a}, \mathbf{1 9 a})$ and $\beta(\mathbf{1 8 b}, \mathbf{1 9 b})$ allylic alcohols. Subsequent $p$-bromobenzoylation and purification by HPLC yielded the $p$-bromobenzoates 18c, 19c, 18d and 19d (Scheme 6).
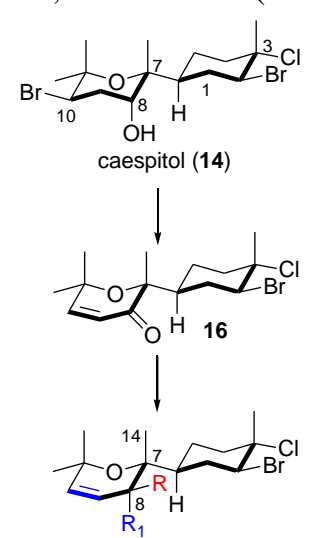

18a $\mathrm{R}_{1}=\mathrm{OH}, \mathrm{R}=\mathrm{H}$

$18 b \mathrm{R}_{1}=\mathrm{H}, \mathrm{R}=\mathrm{OH}$

18c $\mathrm{R}_{1}=\mathrm{OBzBr}, \mathrm{R}=\mathrm{H}(\Delta \varepsilon=-14.9)$

18d $R_{1}=H, R=\operatorname{OBzBr}(\Delta \varepsilon=+6.9)$
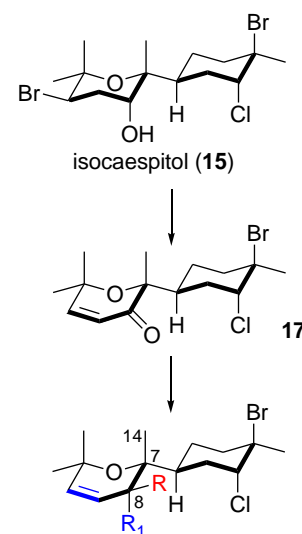

19a $\mathrm{R}_{1}=\mathrm{OH}, \mathrm{R}=\mathrm{H}$

$19 b \mathrm{R}_{1}=\mathrm{H}, \mathrm{R}=\mathrm{OH}$

19c $\mathrm{R}_{1}=\mathrm{OBzBr}, \mathrm{R}=\mathrm{H}(\Delta \varepsilon=-12.8)$

$19 \mathrm{~d} R_{1}=H, R=\operatorname{OBzBr}(\Delta \varepsilon=+3.0)$
Scheme 6. Chemical derivatization of caespitol (14) and isocaespitol (15).

The stereochemistry of this new stereogenic carbon (C8) was determined by nOe experiments. Irradiations of the $\mathrm{H}-$ 14 protons gave rise to enhancements of the $\mathrm{H} 8$ signal in the $\alpha$-benzoates $18 \mathbf{c}$ and $19 \mathbf{c}$, but not in the $\beta$-benzoates 18d and 19d.

ECD of these $p$-bromobenzoylated sesquiterpenes showed a negative Cotton effect at $237 \mathrm{~nm}$ for the $\alpha$-caespitenol (18c, $\Delta \varepsilon=-14.9)$, and for its $\beta$-isomer $(\mathbf{1 8 d}, \Delta \varepsilon=+6.9)$ a positive Cotton effect at $238 \mathrm{~nm}$. The isocaespitenol derivatives exhibited the same behavior, a negative Cotton effect at $237 \mathrm{~nm}$ for the $\alpha$-isomer (19c, $\Delta \varepsilon=-12.8)$ and a positive Cotton effect at $238 \mathrm{~nm}$ for the $\beta$-isomer (19d, $\Delta \varepsilon$ $=+3.0)$. All these ECD data are in complete agreement between them and with the absolute configuration shown for caespitol and isocaespitol in Scheme 6.

Tip 11. In a chemical transformation to obtain epimers is an advantage, since double amount and complementary ECD data can be analysed, as shown for $\mathbf{1 8}$ and $\mathbf{1 9}$.

The ECD allylic benzoate method ${ }^{38,39}$ can also be applied to exo-cyclic allylic alcohols. The following examples are very useful from a teaching point of view. These are hydroazulenoid diterpenes isolated from brown seaweeds of the genus Dictyota, collected in the Canary Islands: three new bicarbocyclic diterpenes, dictyotriols C (20), D (21), and $\mathrm{E}(\mathbf{2 2})$, and several already known: pachydictyol A (23), dictyol B (24), dictyol C (25) and dictyotadiol (26) (Scheme 7). ${ }^{41}$ 


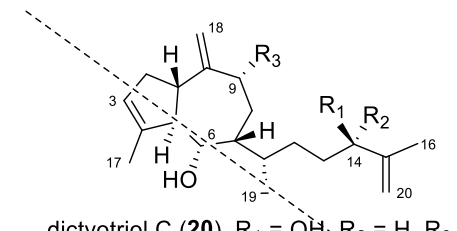

dictyotriol C (20), $\mathrm{R}_{1}=\grave{\mathrm{O}} \mathrm{H}_{2} \mathrm{R}_{2}=\mathrm{H}, \mathrm{R}_{3}=\mathrm{OH}$ dictyotriol D (21), $\mathrm{R}_{1}=\mathrm{H}, \mathrm{R}_{2}=\mathrm{OH}, \mathrm{R}_{3}=\mathrm{OH}$

27, $R_{1}=O B z B r, R_{2}=H, R_{3}=O A c: \Delta \xi^{\prime}=-3.4$

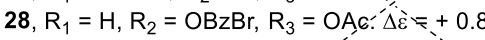

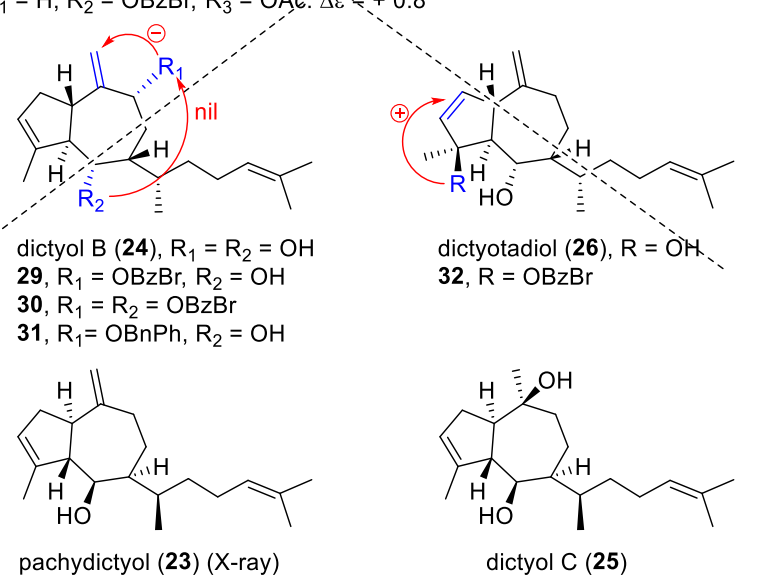

Scheme 7. Diterpenes under dash-cross have the wrong absolute configuration. Pachydictyol A (23) and dictyol C (25) show the corrrect configuration.

For the dictyotriols $\mathrm{C}$ and $\mathrm{D}$, the absolute configuration of the two allylic alcohol moieties were determined independently, one in the side-chain and the other in the ring. Chemical transformation from dictyol B (24) to the allylic $p$-bromobenzoates $\mathbf{2 7}$ and $\mathbf{2 8}$, and subsequent ECD analyses determined the absolute configuration as $14 R(\mathbf{2 7}$, $236 \mathrm{~nm}, \Delta \varepsilon=-3.4)$ and $14 S(\mathbf{2 8}, \Delta \varepsilon=+0.8)$, respectively. To establish the absolute configuration of the exo-cyclic allylic alcohol moieties, dictyol B (24) was chosen as it has no allylic alcohol in the side chain and belongs to the same stereochemical series as dictyotriols C, D, and E. Benzoylation of dictyol B (24) with $p$-bromobenzoyl chloride/silver triflate in $\mathrm{CH}_{2} \mathrm{Cl}_{2}$ /pyridine gave the monobenzoate 29, which showed a negative Cotton effect at $239 \mathrm{~nm}(\Delta \varepsilon=-2.7)$. This negative ECD sign led to the absolute configuration shown for dictyol $\mathrm{B}$, and therefore for the dictyotriols C, D, and E, and dictyotadiol (Scheme 7).

This result was opposite to the absolute configuration of pachydictyol A (23, isolated from the brown alga Pachydictyon coriaceum) using X-ray crystallography, so further studies were carried out. Obtained in a very small amount due to hindering of the hydroxyl group at the 6 position, the dibenzoate $\mathbf{3 0}$ showed no split ECD due to the coplanarity of the two chomophores. Epimerization of compound 29 at C6 was unsuccessful, so oxidation then reduction led to the same starting compound $\mathbf{2 9}$. The 9mono-( $p$-phenylbenzyl ether) $\mathbf{3 1}$ exhibited a negative ECD sign at $247 \mathrm{~nm}(\Delta \varepsilon=-1.1)$, and since $p$-phenylbenzyl ether ${ }^{42}$ can be interpreted analogously to the benzoates in the exciton chirality method, this result supported the same absolute configuration as that obtained from the mono- $p$ bromobenzoate $\mathbf{2 9 . 4 3}$

To be more confident with this result, another diterpenoid was chosen for ECD analysis. Thus, dictyotadiol (26) was $p$-bromobenzoylated similarly to dictyol $\mathrm{B}$ using $p$ bromobenzoyl chloride and silver triflate, and purified by HPLC. This compound 32 exhibited a positive Cotton effect at $235 \mathrm{~nm}(\Delta \varepsilon=+5.0)$, supporting the same configuration as that obtained from dictyol B (Scheme 7). Two years later however, ECD analysis of a new diterpene 9-epi-dictyol B (33), ${ }^{44}$ isolated from the brown alga Glossophora kuntii, led to the same absolute configuration as that reported for pachydictyol A (23) and to revising those of the previously reported diterpenoids: dictyotriols C (20), D (21), and E (22), dictyol B (24), and dictyotadiol (26) (Scheme 8).

The negative Cotton effect at $246 \mathrm{~nm}(\Delta \varepsilon=-3.3)$ of the monobenzoate of epi-dictyol B (34) was unexpected since it showed the same sign as its epimer 29. Although natural products with identical skeletons can exist in nature with opposite absolute configurations, this rarely occurs.

Chemical transformation of 9-epi-dictyol B into dictyol B confirmed that both diterpenes belong to the same stereochemical series. Further confirmation came from the bis-( $p$-bromobenzoate) of 9-epi-dictyol B (35), which exhibited a split ECD curve with Cotton effects at $250 \mathrm{~nm}$ $(\Delta \varepsilon=+15.0)$ and a second Cotton effect at $231 \mathrm{~nm}(\Delta \varepsilon=$ -1.8 ), and from the definitive chemical transformation of pachydictyol A (23) into 9-epi-dictyol B (33).

Then why do the two epimeric allyl benzoates 29 and 34 both exhibit the same negative sign?

Molecular mechanics calculations of 9-epi-dictyol B (33) and dictyol B (24), and their corresponding monobenzoates 34 and 29, revealed that the most stable conformation is the twist-chair, and unexpectedly that both epimers had an unusual negative dihedral angle O9-C9-C10-C18. Values of -112.9 and -7.2 were obtained for the monobenzoates of 9-epi-dictyol B and dictyol B respectively, in agreement with both the exciton chirality method. The negative dihedral angle for the latter compound was not observed in Dreiding models used in the first study, since all conformers showed positive values. They thus led to a mistaken interpretation of the ECD data. The utility of molecular mechanics was demonstrated, especially for non-rigid rings.

Tip 12. With non-rigid cycles, a deep conformational analysis is strongly recommended. 


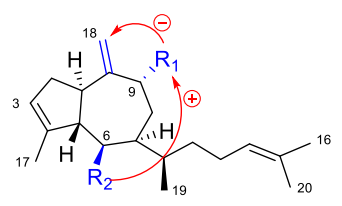

9-epi-dictyol $\mathrm{B}(33), \mathrm{R}_{1}=\mathrm{R}_{2}=\mathrm{OH}$ 34, $\mathrm{R}_{1}=\mathrm{OBzBr}, \mathrm{R}_{2}=\mathrm{OH}$

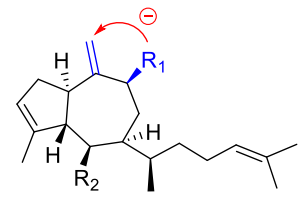
29, $\mathrm{R}_{1}=\mathrm{OBzBr}, \mathrm{R}_{2}=\mathrm{OH}$ dictyol $\mathrm{B}(\mathbf{2 4}), \mathrm{R}_{1}=\mathrm{R}_{2}=\mathrm{OH}$ $35, \mathrm{R}_{1}=\mathrm{OBzBr}, \mathrm{R}_{2}=\mathrm{OBzBr}$

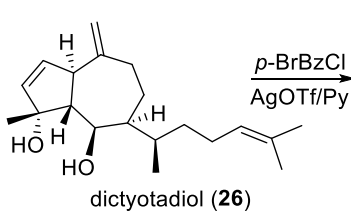

$\mathrm{zBr}$

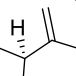<smiles>[CH]1CCCC1</smiles>

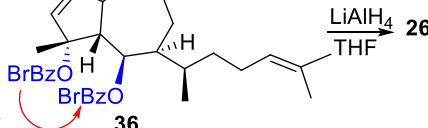

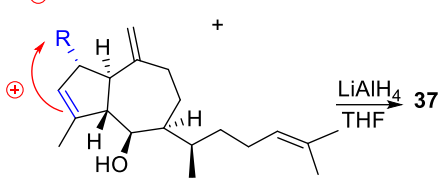

32, $\mathrm{R}=\mathrm{OBzBr}$ (rearranged)<smiles>[R3]C1C[C@H]([C@H](C)CCC([R])([R])C(=C)C)[C@H](O)[C@@]2(C)C(C)=CC[C@H]2C1=C</smiles><smiles>[R]C1C[C@H]([C@H](C)C/C=C/C(C)(C)O)[C@H](O)[C@@]2(C)C(=C)[C@@H]1CC=C2C</smiles>

dictyotriol C (20), $\mathrm{R}_{1}=\mathrm{OH}, \mathrm{R}_{2}=\mathrm{H}, \mathrm{R}_{3}=\mathrm{OH}$ dictyotriol $\mathrm{E}(\mathbf{2 2}), \mathrm{R}=\mathrm{OH}$ dictyotriol $\mathrm{D}$ (21), $\mathrm{R}_{1}=\mathrm{H}, \mathrm{R}_{2}=\mathrm{OH}, \mathrm{R}_{3}=\mathrm{OH}$

Scheme 8. All diterpenes with the correct absolute configuration.

Further research regarding dictyotadiol (26) provided ECD data and also attributed the opposite absolute configuration to pachydictyol A (23). Thus, $p$-bromobenzoylation of $\mathbf{2 6}$ yielded the bis( $p$-bromobenzoate) derivative $\mathbf{3 6}$ and the mono- $p$-bromobenzoate derivative 32. The former exhibited only a negative first Cotton effect at $\lambda_{\text {ext }}=249$ $\mathrm{nm}(\Delta \varepsilon=-26.7)$. Based on the bathochromic shift $\left(\lambda_{\max }=\right.$ $243 \mathrm{~nm}, \varepsilon=38200$ ) and its intensity, this ECD spectrum belongs to the exciton split type, therefore the dibenzoate chirality method was applied. Thus, this negative Cotton effect corresponds to the absolute configuration shown for the dibenzoate $\mathbf{3 6}$ and dictyotadiol $\mathbf{2 6}$ in Scheme 8. Moreover, reduction with $\mathrm{LiAlH}_{4}$ in THF led to the starting material 26

The mono-p-bromobenzoate derivative 32 showed identical spectroscopic data, including ECD data, to the previously reported monobenzoate of dictyotadiol. Careful ${ }^{1} \mathrm{H}$ NMR analysis of this compound and comparison with compounds $\mathbf{2 6}$ and $\mathbf{3 6}$ revealed a few small differences in the chemical shifts of the methyl group 17 and hydrogens at positions 2 and 3. Reduction of $\mathbf{3 2}$ with $\mathrm{LiAlH}_{4}$ did not lead to dictyotadiol (26) but to the allylic alcohol 37, via an allylic rearrangement of the benzoate group from $\mathrm{C}-4$ to $\mathrm{C}$ 2. The positive Cotton effect for this rearranged compound is now in total agreement with the absolute configuration shown in Scheme 8 and with the whole series.

The unexpected dihedral angle between the benzoate and the exo-cyclic double bond in dictyol B was only observed by molecular mechanics calculations, This angle and the allylic rearrangement in dictyotadiol during its benzoylation led to the wrong absolute configuration for the diterpenes shown in dash-cross in Scheme 7. The $14 R$ and $14 S$ absolute configurations for dictyotriols $\mathrm{C}$ and $\mathrm{D}$ respectively are correct, since they were determined independently.

Medium- and macro-cyclic compounds have conformational properties that are quite useful for stereochemical control in synthetic intermolecular reactions. ${ }^{45}$ Thus, the iodine-induced transannular ring expansion of the cyclononyl epoxide derivative $\mathbf{4 1}$ led to the iodine-containing oxacycles $\mathbf{4 3}$ and $\mathbf{4 4}$. Likewise, the diepoxide 45 gave the 10-oxabicycles 46 and 47 by treatment with $\mathrm{TiCl}_{2}(\mathrm{O}-\mathrm{i}-\mathrm{Pr})_{2}$ in $\mathrm{CH}_{2} \mathrm{Cl}_{2}$ at $-78^{\circ} \mathrm{C}$ (Scheme 9). ${ }^{46}$

The kinetic resolution of the racemic allyl alcohol $\mathbf{3 8}$ was performed by the enantioselective Sharpless epoxidation, ${ }^{47}$ with high yield, conversion, and ee (>99\%) by using 1.5 equiv. of (+)-DCHT.

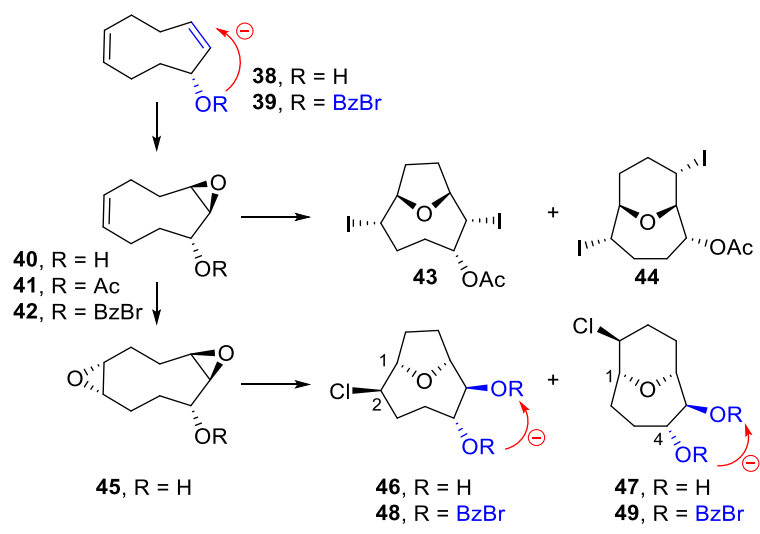

Scheme 9. Kinetic resolution, absolute determination, and stereocontrol reactions of cyclononyl systems.

Although the absolute configuration of (-)-38 was successfully determined by applying the allylic benzoate method, ${ }^{38,39}$ the more rigid and X-determined bicycle $\mathbf{4 6},{ }^{46}$ as well as $\mathbf{4 7}$, were used to apply the dibenzoate chirality method. ${ }^{5,16,17}$ Therefore, $\mathbf{4 6}$ and $\mathbf{4 7}$ were $p$ bromobenzoylated and their respective derivatives $\mathbf{4 8}$ and 49 analyzed by ECD. Both compounds showed $\lambda_{\max }=243$ $\mathrm{nm}$, negative first Cotton effects at $251 \mathrm{~nm}(\mathbf{4 8}, \Delta \varepsilon=-39.5$; 49, $\Delta \varepsilon=-41.5)$ and positive second Cotton effects at 234 nm $(\mathbf{4 8}, \Delta \varepsilon=+18.9 ; 49, \Delta \varepsilon=+16.1)$. These ECD data led to the absolute configuration shown for these compounds (Scheme 9) and by extension to that of compound (-)-38. This result is in agreement with the finding that when (+)tartrates are used in the kinetic resolution of racemic allylic alcohols, ${ }^{47}$ the fast-reacting enantiomer normally has the $S$ absolute configuration.

One conformation of the cyclononyl system was analyzed by molecular mechanics and ECD. The most stable rotamer found ( $86 \%$ population) (Figure 12) has a O-C1-C2-C3 dihedral angle of -135 . Its sign is in accordance with the negative one obtained by ECD for compound 39. Low temperature ECD measurement revealed a slight increase in its negative Cotton effect $242 \mathrm{~nm}(\mathrm{EtOH})$, from $\Delta \varepsilon=$ $-5.7\left(\mathrm{~T}=20^{\circ} \mathrm{C}\right)$ to $\Delta \varepsilon=-6.2\left(\mathrm{~T}=-110^{\circ} \mathrm{C}\right)$, in agreement with elimination of the less stable conformers with positive ECD contribution (not shown). 
This conformation explains the threo stereostructure of the epoxy-alcohol 40, the similar conformation obtained for 40, and the stereochemistry of the trans-bisepoxy-alcohol 45. Thus, the stereochemistry for these compounds is conformationally controlled.
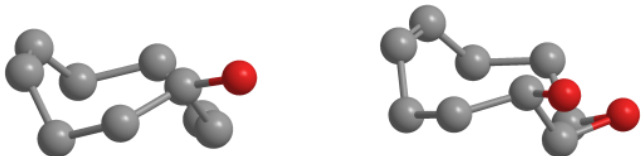

Figure 12. Most stable conformer for the cyclononyl 38 (left), and the epoxy-alcohol $\mathbf{4 0}$ (right).

A similar conformational analysis was performed for the (2Z,5E,9Z)-cyclododeca-2,5,9-trienol (50) (Scheme 9), ${ }^{48}$ the most stable conformers found explaining the threo stereostructure of 52. The racemic allyl alcohol $\mathbf{5 0}$ was resolved by conversion into its acid phthalate ester, and then resolved by means of the alkaloid (-)-brucine. In this case, the Sharpless kinetic resolutions and the use of chiral derivatizing reagents were both unsuccessful.

The stereostructure of the oxabicycles $\mathbf{5 5}$ and $\mathbf{5 6}$ were predictable from the conformational analysis of the epoxyalcohol 52.

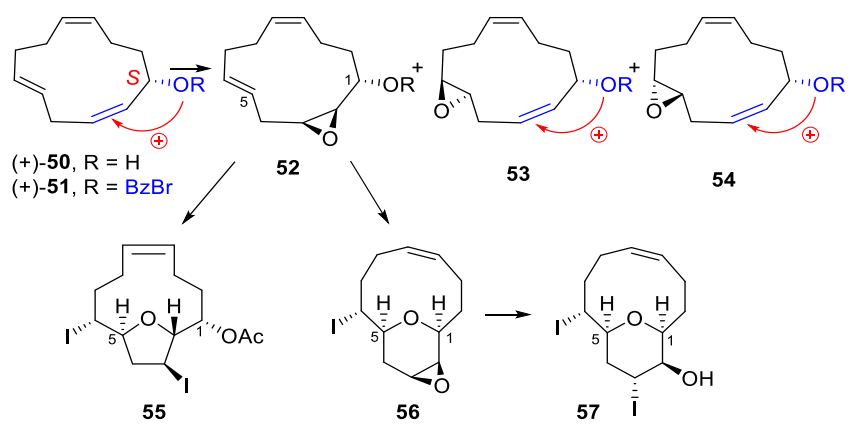

Scheme 9. Cyclododeca-2,5,9-trien-1-ol (50) and derivatives.

Let us now consider an example of an acyclic allylic alcohol deserving comment. From the red alga Laurencia obtusa two novel sesquiterpenes, puertitol A (58) and B (59) were isolated and their structures elucidated (Scheme 10)..$^{49}$ Once the relative configurations were established by nOe difference experiments, the absolute configuration and conformation of puertitol B (59) was found by applying the ECD acyclic allylic benzoate method. ${ }^{39}$ Benzoylation of puertitol B with 4-bromobenzoyl chloride in pyridine and subsequent HPLC purification led to the $p$-bromobenzoate derivative 60. This compound displayed a rather large positive Cotton effect for this type of system $(\Delta \varepsilon=+16.1$, $238 \mathrm{~nm}$ ), but to establish its absolute configuration its conformation had to be checked. The side chain is free to rotate and three rotamers can be expected (Scheme 10, bottom). While rotamer $\mathrm{b}$ cannot contribute to the split ECD, due to the coplanarity of the double bond and the ${ }^{1} \mathrm{~L}_{\mathrm{a}}$ transition of the $p$-bromobenzoate, conformers a and $\mathrm{c}$ possess opposite sign. This problem is easily solved by measuring the coupling constant between the carbinol H9 and the olefinic H10. In this particular case, the $J_{\mathrm{H} 9-\mathrm{H} 10}$ is
$9.4 \mathrm{~Hz}$, meaning that the most stable conformer is c, where the double bond eclipses the carbonyl hydrogen. Moreover, the H9 signal was transformed into a clear triplet when $\mathrm{H} 10$ was irradiated. Therefore, the positive sign established an $S$ absolute configuration at C9.

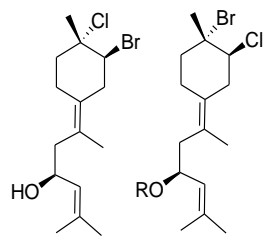

58 59. $\mathrm{R}=\mathrm{H}$ 60. $\mathrm{R}=p-\mathrm{Br}-\mathrm{Bz}$

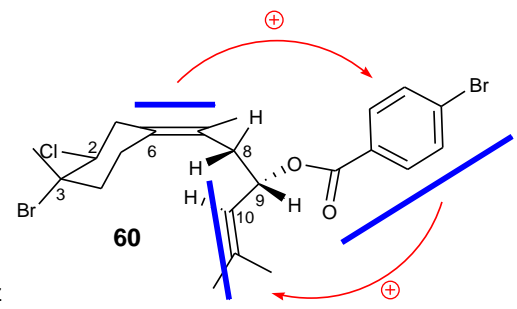

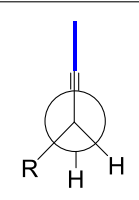

b

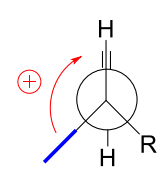

C
Scheme 10. Top: Structure of puertitols A (58), B (59), and the $p$ bromobenzoyl derivative 60. Bottom: Three possible rotamers and their corresponding ECD signs.

The original acyclic allylic benzoate method study, developed by Sharpless and Nakanishi, ${ }^{39}$ contained many examples and in all of them enantiomers with the $S$ absolute configuration gave rise to positive Cotton effects, whereas those with the $R$ configuration were negative. The amplitude of this type of Cotton effect is normally low; the highest was around 12 .

Tip 13. The conformation of an acyclic allylic system should be checked by analyzing the NMR coupling constant between the carbinyl and vinyl protons.

The amplitude of puertitol B benzoate (60) was 16.1, pointing to a positive influence of the interaction between the homoallylic double bond and the $p$-bromobenzoate in the total spectrum (Scheme 10).

A few years later, an ECD study of homoallylic benzoates confirmed the action of the exciton coupling interaction in homoallylic systems too. ${ }^{50}$ In addition, a simple exciton ECD method for determining absolute configuration of primary allylic amines was proposed through the formation of their N-phthaloyl derivatives. ${ }^{51}$

Triazoles have a broad range of biological activities. ${ }^{52,53,54}$ In particular, they have been widely used as a linker to join two molecules or macromolecules, many interesting entities being synthesized. ${ }^{55,56}$ For this reason, triazolyl derivatives were studied as chromophores in ECD studies. ${ }^{57}$ The results show that 4-substituted aryl triazoles are chromophores useful in determining absolute configurations by ECD, as they give rise to excitoncoupled curves (Figure 13). 


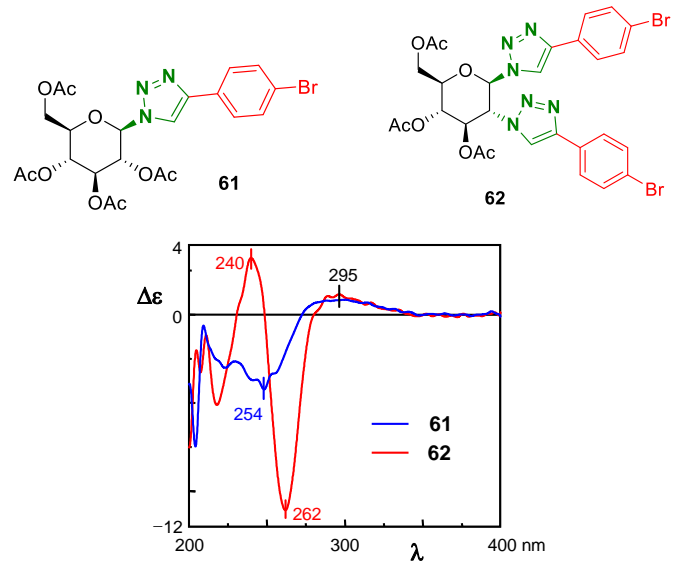

Figure 13. CD spectra of triazolyl derivatives 61 (blue) and $\mathbf{6 2}$ (red) $\left(\mathrm{CH}_{3} \mathrm{CN}\right)$.

However, the interpretation of these spectra is not straightforward, since the 4-phenyl triazole chromophore can adopt different orientations to the chiral scaffold by rotating the $\mathrm{N}-\mathrm{C}$ bond (rotamerism), consequently changing the direction of the transition dipole moment. This is not a symmetric chromophore. Therefore, molecular mechanics and semi-empirical calculations (PC Model and MOPAC) for compound 62 show there are several rotamers (Scheme 11). The most stable (rotamer F) and the third most (rotamer $\mathrm{C}$ ) have a negative dihedral angle between their corresponding transition dipole moments, which explains the observed negative CD sign. The positive corresponding dihedral angle of $\mathrm{E}$ and the other rotamers in turn explains the smaller CD couplet amplitude of ca. 15 delta epsilon exhibited for 62 , compared to the classical $p$-bromobenzoate of ca. 50 for a 1,2-trans-disubstituted system. ${ }^{5}$
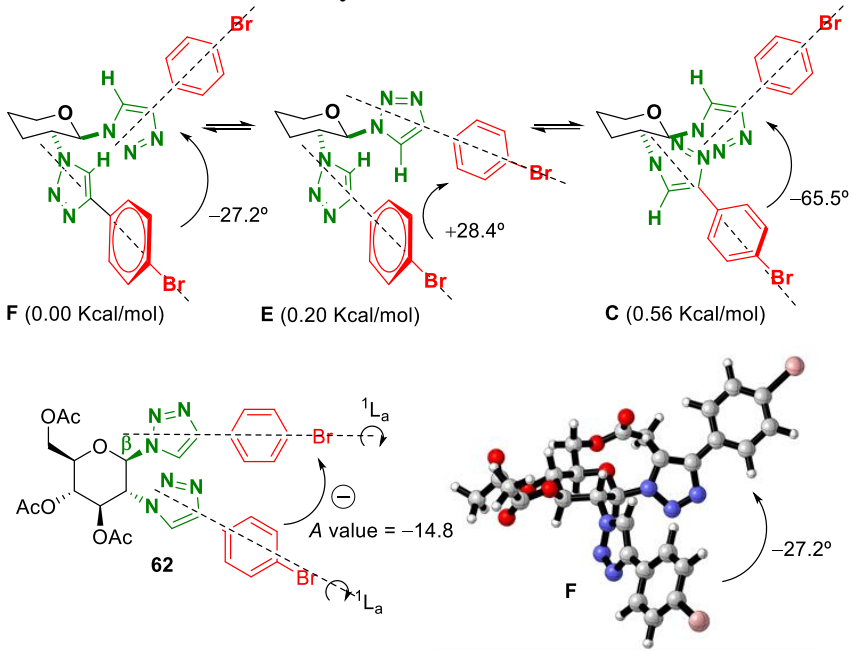

Scheme 11. The three lowest energy conformations of the $\beta$ glucopyranoside 62 (MOPAC).

Compounds with an alpha anomeric configuration, 1,2-cisdisubstituted system, exhibited ECD spectra of the same sign as the beta anomers, and with higher intensities. Conformational analysis of compound $\mathbf{6 3}$ showed only one rotamer with less than $3 \mathrm{kcal} / \mathrm{mol}$, with respect to the others. Scheme 12 shows some spectroscopic NMR data in complete agreement with this conformation. The negative dihedral angle $(\phi=-28.0)$ between its electric transition moments is in total agreement with the observed negative CD couplet $(A=-23.8)$. Previous X-ray analysis ${ }^{53,58}$ of an $\alpha$-triazolyl compound showed this preferred disposition of the triazolyl group at the anomeric position.
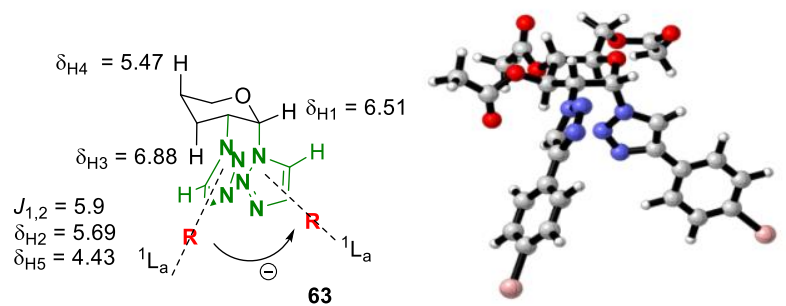

Scheme 12. The most stable rotamer for the $\alpha$-glucopyranoside $\mathbf{6 3}$ (MOPAC) and spectroscopic data.

The behavior of the $p$-bromophenyl triazole under a heteroexciton coupling interaction was tested. ${ }^{5,16}$ Compounds 64 and 65 were prepared and analyzed, constituting a bichromophoric system with two chromophores absorbing at different $\lambda_{\max }$, (Figure 14). These compounds showed $\lambda_{\max }$ at the wavelength of the triazolyl chromophore $(250 \mathrm{~nm})$ and split Cotton effects with signs in agreement with their chiralities (Scheme 13). Thus, compound 64 showed a negative first Cotton effect at $258(-21.5)$ and a positive second Cotton effect at $240 \mathrm{~nm}(+12.0)(A=-33.5)$, whereas compound $\mathbf{6 5}$ had Cotton effects at $258(+30.9)$ and $239 \mathrm{~nm}(-11.4),(A=+42.3)$.

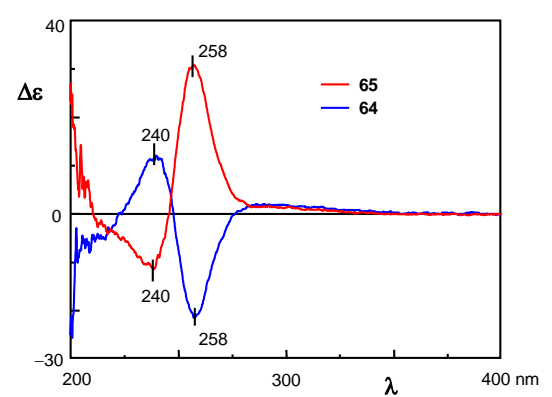

Figure 14. CD spectra of compounds 64 (blue) and 65 (red) $\left(\mathrm{CH}_{3} \mathrm{CN}\right)$.

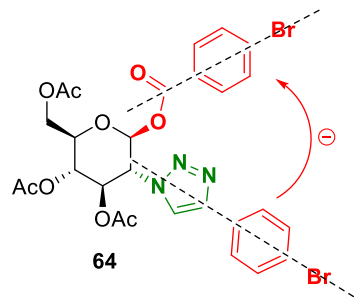<smiles>CC(=O)OCC1O[C@H](n2cc(-c3ccc(Br)cc3)nn2)[C@H](OC(C)=O)[C@@H](OC(C)=O)[C@H]1OC(C)=O</smiles>

Scheme 13. Negative/positive chirality between the ${ }^{1} \mathrm{~L}_{\mathrm{a}}$ band transitions of the triazolyl chromophores of compound 64 and 65 , respectively.

The signs of these CD couplets are in total agreement with the chirality of these molecules, and with the dihedral angle $\mathrm{O} 1-\mathrm{C} 1-\mathrm{C} 2-\mathrm{N} 2$. In addition, the observed amplitudes are greater than those of their analogous compounds with two 
4-aryl triazoles, compounds $62(A=-14.8)$ and $63(A=$ -23.8). The higher amplitude of the split ECD curves for these compounds may be explained by a reduction in the number of conformers, by substituting a 4-aryl triazole with a highly symmetric 4-bromobenzoate. This demonstrates that the 4-bromophenyl triazole can be successfully used in conjunction with another type of chromophore for exciton-coupled ECD analysis. It provides the added benefit of simplifying the corresponding conformational analysis.

This study confirms that when two $p$-bromophenyl triazoles are in equatorial disposition (1,2-transconfiguration) they show their Cotton effects in agreement with the sign of the dihedral angle of the $\mathrm{C}-\mathrm{N}$ bonds. Nevertheless, when one $p$-bromophenyl triazole is in an axial disposition (1,2-cis-configuration) they have the opposite sign to it. Therefore, much care must be taken with this cis relative configuration.

1. Djerassi, C. Optical Rotatory Dispersion, Applications to Organic Chemistry, McGraw-Hill Book Company: New York, 1960.

2. Crabbé, P. Optical Rotatory Dispersion and Circular Dichroism in Organic Chemistry, Holden-Day: San Francisco, 1965.

3. Optical Rotatory Dispersion and Circular Dichroism in Organic Chemistry, Snatzke, G. ed., Heyden \& Son Ltd.: London, 1967.

4. Fundamental Aspects and Recent Developments in Optical Rotatory Dispersion and Circular Dichroism (F. Ciardelli, and P. Salvadori, eds.), Heyden \& Son Ltd.: London, 1973.

5. Harada, N.; Nakanishi, K. Circular Dichroic Spectroscopy. Exciton Coupling in Organic Stereochemistry, University Science Books: California, 1983.

6. a) Circular Dichroism: Principles and Applications, 2nd Ed., (Eds.: Berova, N.; Nakanishi, K.; Woody, R. W.), Wiley-VCH, New York, N. Y., 2000. b) Lightner, D. A.; Gurst, J. E. Conformational Analysis and Stereochemistry from Circular Dichroism Spectroscopy, Wiley-VCH, New York, N. Y., 2000.

7. Berova, N.; Polavarapu, P. L.; Nakanishi, K.; Woody, R. W. Comprehensive Chiroptical Spectroscopy: Instrumentation, Methodologies, and Theoretical Simulations; John Wiley \& Sons: New York, NY, USA, 2012.

8. Berova, N.; Polavarapu, P. L.; Nakanishi, K.; Woody, R. W. Comprehensive Chiroptical Spectroscopy: Applications in Stereochemical Analysis of Synthetic Compounds, Natural Products, and Biomolecules; John Wiley \& Sons: New York, NY, USA, 2012.

9. Ranjbar, B.; Gill, P Chem. Biol. Drug Des. 2009, 74, 101-120. 10. Circular Dichroism and the Conformational Analysis of Biomolecules (G. D. Fasman, ed.), Plenum Press: New York, p. 25-157 (1996).

11. Pescitelli, G.; Di Bari, L.; Berova, N. Chem. Soc. Rev. 2011, 40, 4603-4625.

12. Pescitelli, G.; Di Bari, L.; Berova, N. Chem. Soc. Rev. 2014, 43, 5211-5233.

13. Gawronski, J. K.; Walborsky, H. M. The Diene Chirality in Circular Dichroism: Principles and Applications, 2nd Ed., (Eds.: Berova, N.; Nakanishi, K.; Woody, R. W.), Wiley-VCH: New York, N. Y., 2000, pp 301-334.
It can be concluded that ECD is a powerful and sensitive technique to determine absolute configurations and conformations of both natural and synthetic compounds in solution. In particular, the exciton chirality method facilitates these determinations non-empirically. Moreover, the straightforward spectral interpretation in this technique makes it very useful for stereochemistry studies, owing to the general validity of the pairwise additivity in exciton-coupled systems.

\section{Acknowledgments}

This work was supported by the Spanish MINECO, cofinanced by the European Regional Development Fund (ERDF) CTQ2014-56362-C2-1-P.

\section{References and Notes}

14. Lighter, D. A. The Octant Rule in Circular Dichroism: Principles and Applications, 2nd Ed., (Eds.: Berova, N.; Nakanishi, K.; Woody, R. W.), Wiley-VCH: New York, N. Y., 2000, pp 259-299.

15. (a) Sanhueza, C. A.; Arias, A. C.; Dorta, R. L.; Vázquez, J. T. Tetrahedron:Asymmetry 2010, 21, 1830-1832. (b) Sanhueza, C. A.; Dorta, R. L.; Vázquez, J. T. J. Org. Chem. 2011, 76 (19), 7769-7780

16. Harada, N.; Nakanishi, K.; Berova, N. Electronic CD Exciton Chirality Method: Principles and Applications in Comprehensive Chiroptical Spectroscopy: Applications in Stereochemical Analysis of Synthetic Compounds, Natural Products, and Biomolecules; Berova, N.; Polavarapu, P. L.; Nakanishi, K.; Woody, R. W. (Eds.); John Wiley \& Sons: New York, NY, USA, 2012.

17. Harada, N.; Nakanishi, K. J. Am. Chem. Soc. 1969, 91, 3989. 18. The difference $\Delta \varepsilon=\varepsilon_{\mathrm{L}}-\varepsilon_{\mathrm{R}}$ is called circular dichroism. While biochemists use molar ellipticity [ $\theta]$, organic chemists prefer $\Delta \varepsilon$. In practice, the following equations are useful: (1) $\Delta \varepsilon=\theta / 33 \mathrm{c} \mathrm{l}$; $\theta$ : observed ellipticity angle; 1 : cell length in $\mathrm{cm}$; $\mathrm{c}$ : concentration in mol (solute) / L (solution). (2) $[\theta]=3300 \Delta \varepsilon$.

19. Amplitude or $A$ value is the difference between the $\Delta \varepsilon$ values of the two extrema of split CD curves. $A=\Delta \varepsilon_{1}-\Delta \varepsilon_{2}$. The sign of the $A$ value corresponds to that of the first Cotton effect.

20. At concentrations lower than $0.01 \mathrm{M}$, the molar extinction coefficient $\varepsilon$ is almost constant, so that the Beer-Lambert law can be considered accurate at these concentrations.

21. Spectroscopic or HPLC solvents must be used, acetonitrile being very common.

22. Gortázar, P.; Vázquez, J. T. J. Pharm. Sci. 1994, 83, 12041208.

23. Gortázar, P.; Ravina, M.; Vázquez, J. T. J. Pharm. Sci. 1995, 84, 1316-1321.

24. Gortázar, P.; Roën, A.; Vázquez, J. T. Chirality 1998, 10, $507-$ 512 .

25. Liu, H. W.; Nakanishi, K. J. Am. Chem. Soc. 1982, 104, 1178. 26. (a) Wiesler, W. T.; Vázquez, J. T.; Nakanishi, K. J. Am. Chem. Soc. 1986, 108, 6811-6813. (b) Wiesler, W. T.; Vázquez, J. T.; Nakanishi, K. J. Am. Chem. Soc. 1987, 109, 5586-5592. (c) Vázquez, J. T.; Wiesler, W. T.; Nakanishi, K. Carbohydr. Res. 1988, 176, 175-194. 
27. (a) Wiesler, W. T.; Nakanishi, K. J. Am. Chem. Soc. 1989, 111, 3446-3447; (b) ibid, 1989, 111, 9205-9213.; (c) ibid, 1990, $112,5574-5601$.

28. Zhou, P.; Berova, N.; Nakanishi, K.; Rohmer, M. J. Chem. Soc. Chem. Commun. 1991, 256-258.

29. González, A. G.; Nuñez, M. P.; Ravelo, A. G.; Luis, J. G.; Jiménez, I. A.; Vázquez, J. T. Heterocycles 1989, 29, 2287-2296. 30. (a) Muñoz, O. M.; González, A. G.; Ravelo, A. G.; Luis, J. G; Vázquez, J. T.; Nuñez, M. P.; Jiménez, I. A. Phytochemistry 1990, 29, 3225-3228. (b) González, A. G.; Luis, J. G.; Grillo, T. A.; Vázquez, J. T. J. Nat. Prod. 1991, 54, 579-581.

31. González, A. G.; Nuñez, M. P.; Ravelo, A. G.; Sazatornil, J. G.; Vázquez, J. T.; Bazzocchi. I.; Morales, E. Q.; Muñoz, O. M. J. Chem. Soc. Perkin Trans 1 1992, 1437-1441.

32. Perestelo, N. R.; Jiménez, I. A.; Tokuda, H.; Vázquez, J. T.; Ichiishi, E.; Bazzocchi, I. L. J. Nat. Prod. 2016, 79, 2324-2331.

33. Lin, Y-Y.; Risk, M.; Ray, S. M.; Van Engen,D.; Clardy, J.; Golik, J.; James, J. C.; Nakanishi, K. J. Am. Chem. Soc. 1981, 103, 6773-6775.

34. Shimizu, Y.; Chou, H-N.; Bando, H.; Van Duyne, G.; Clardy J. C. J. Am. Chem. Soc. 1986, 108, 514-515.

35. Shimizu, Y.; Bando, H.; Chou, H-N.; Van Duyne, G.; Clardy J. C. J. Chem. Soc., Chem. Commun. 1986, 1656-1658.

36. Pawlak, J.; Tempesta, M. S.; Golik, J.; Zagorski, M. G.; Lee, M. S.; Nakanishi, K.; Iwashita, T.; Gross, M. L.; Tomer, K. B. J. Am. Chem. Soc. 1987, 109, 1144-1150.

37. Matile, S.; Berova, N.; Nakanishi, K.; Fleischhauer J.; Woody, R. W. J. Am. Chem. Soc. 1996, 118, 5198-5206.

38. (a) Harada, N.; Iwabuchi, J.; Yokota, Y.; Uda, H.; Nakanishi, K. J. Am. Chem. Soc. 1981, 103, 5590-5591.

39. Gonnella, N. C.; Nakanishi, K.; Martín, V. S.; Sharpless B. J. Am. Chem. Soc. 1982, 104, 3775-3776

40. Chang, M.; Vázquez, J. T.; Nakanishi, K.; Cataldo, F.; Estrada, D. M.; Fernández, J.; Gallardo, A.; Martín, J. D.; Norte, M.; Pérez, R.; Rodríguez, M. L. Phytochemistry 1989, 28, 14171424.

41. Vázquez, J. T.; Chang, M.; Nakanishi, K.; Manta, E.; Pérez, C.; Martín, J. D. J. Org. Chem. 1988, 53, 4797-4800.

42. Takeda, R.; Zask, A.; Nakanishi, K.; Park, M. H. J. Am. Chem. Soc. 1987, 109, 914.

43. This chromophore is useful when dealing with hindered hydroxyls. Takeda, R.; Park, M. H.; Nakanishi, K. Israel J. Chem. 1989, 29, 239-242.

44. Arroyo, P.; Norte, M.; Vázquez, J. T.; Nakanishi, K. J. Org. Chem. 1991, 56, 2671-2675.
45. (a) Alvarez, E.; Manta, E.; Martín J. D.; Rodríguez, M. L.; Ruiz-Pérez, C. Tetrahedron Lett. 1988, 29, 2093. (b) Alvarez, E.; Manta, E.; Martín J. D.; Rodríguez, M. L.; Ruiz-Pérez, C.; Zurita, D. ibid, 1988, 29, 2097.

46. Morales, E. Q.; Vázquez, J. T.; Martín, J. D. Tetrahedron: Asymmetry 1990, 1, 319-328.

47. (a) Martín, V. S.; Woodward, S. S.; Katsuki, T.; Yamada, Y.; Ikeda, M.; Sharpless, K. B. J. Am. Chem. Soc. 1981, 103, 6237. (b) Gao, Y. Hanson, R. M.; Klunder, J. M.; Ko, S. Y.; Masamune, H.; Sharpless, K. B. J. Am. Chem. Soc. 1987, 109, 5765.

48. Padrón, J. I.; Vázquez, J. T.; Morales, E. Q.; Zárraga, M.; Martín, J. D. Tetrahedron: Asymmetry 1992, 3, 415-430.

49. Vázquez, J. T.; Chang, M.; Nakanishi, K.; Martín J. D.; Martín, V. S.; Pérez, R. J. Nat. Prod. 1988, 51, 1257-1260.

50. Humpf, H.-U., Berova, N.; Nakanishi, K. Jarstfer, M. B.; Poulter. C. D. J. Org. Chem. 1995, 60, 3539-3542.

51. Skowronek, P.; Gawronski, J. Tetrahedron Lett. 2000, 41, 2975-2977.

52. a) Biological Properties of $1 \mathrm{H}-1,2,3-$ and $2 \mathrm{H}-1,2,3-$ Triazoles, da Silva, F. C.; Cardoso, M. F.; Ferreira, P. G.; Ferreira, V. F. in Chemistry of 1,2,3-triazoles (Eds.: Dehaen, W.; Bakulev, V. A.), Top Heterocycl. Chem. 40, Springer-Verlag, Berlin, Heidelberg, 2015, pp. 117-166. b) Zhang, H.-Z.; Wei, J.-J.; Kumar, K. V. Med. Chem. Res. 2015, 24, 182-196.

53. Dedola, S.; Hughes, D. L.; Nepogodiev, S. A.; Rejzek, M.; Field, R. A. Carbohydr. Res. 2010, 345, 1123-1134.

54. a) Bokor, E.; Docsa, T.; Gergely, P.; Somsàk, L. Bioorg. Med. Chem. 2010, 18, 1171-1180; b) Goyard, D.; Docsa, T.; Gergely, P.; Praly, J.-P.; Vidal, S. Carbohydr. Res. 2015, 402, 245-251.

55. (a) Chow, H.-F.; Lau, K.-N.; Ke, Z.; Liang, Y.; Lo, C.-M. Chem. Commun. 2010, 46, 3437-3453; (b) Schulze, B.; Schubert, U. S. Chem. Soc. Rev. 2014, 43, 2522-2571, and references therein.

56. (a) Mangunuru, H. P. R.; Yerabolu, J. R.; Liu, D.; Wang, G. Tetrahedron Lett. 2015, 56, 82-85; (b) Babu, S. S.; Praveen, V. K.; Ajayaghosh, A. Chem. Rev. 2014, 114, 1973-2129; (c) Terech, P.; Weiss, R. G. Chem. Rev. 1997, 97, 3133-3159; d) Cravotto, G.; Cintas, P. Chem. Soc. Rev. 2009, 38, 2684-2697.

57. Tejera, S.; Dorta, R. L.; Vázquez, J. T. Tetrahedron: Asymmetry 2016, 27, 896-909.

58. Wilkinson, B. L.; Bornaghi, L. F.; Houston, T. A.; Poulsen, S.-A.; White, A. R. Acta Cryst. 2006, E62, o5065-05067. 